\title{
Sliding Mode Self-Tuned Single Neuron PID Controller for Power System Stabilizer
}

\author{
MOHAMED ABDEL GHANY ${ }^{1}$, MOHAMED ABDELBAR SHAMSELDIN ${ }^{2}$ \\ ${ }^{1,2}$ Faculty of Engineering \\ ${ }^{1}$ October 6 University, EGYPT \\ ${ }^{2}$ Future University in Egypt, EGYPT
}

\begin{abstract}
In this paper, a modified technique based on the combination of the Single Neuron PID (SNPID), as the main controller and Sliding Mode Control (SMC), as an adaptation technique, to design an optimized selftuned for SNPID controller that may overcome difficulties faced when a change in system operating points occurs. The proposed approach has been implemented as a power system stabilizer (PSS) for a synchronous generator connected to an infinite bus. The Flower Pollination (FP) optimization is based on an appropriate objective function. To demonstrate the effectiveness of the combination obtained controllers, PSS, is tested under different operating conditions. The combination controllers are shown through uncertainties system parameters changes under different disturbances. The results show the ability of the suggested controllers to enhance well the system performances.
\end{abstract}

\section{Key-Words: - Power System Stabilizer (PSS) Single Neuron PID (SNPID) Sliding Mode Control} (SMC) Flower pollination (FP)

Received: May 17, 2021. Revised: October 9, 2021. Accepted: October 23, 2021. Published: November 9, 2021.

\section{Introduction}

The stability of electrical power systems represents one of the main issues concerning electric utilities. The area of concern is the small-signal stability which is the ability of the system to retain synchronism after a small disturbance [1]. PSS is used to damp the low-frequency oscillation, which is a result of generation and load patterns and different power system disturbances like torque and mechanical power. The changes in operating conditions of PSS are an obstacle to adapting the controller parameters [2]. Therefore, the latest studies are interested to implement a high level of control techniques, in which controllers adapt with the continuous change in operating points [3].

The PID controller is a linear controller and is commonly used in engineering applications because of its simple structure and satisfying system dynamics. It's adjusted to enhance both system stability and system behavior. For such purpose, numerous techniques were recommended in particular, intelligent methods (Genetic Algorithm (GA), Neuro-Genetic Technique, Dynamic Programming Algorithm, Evolutionary Programming (EP), Robust Optimization, Simulated Annealing (SA), Bacterial Foraging Algorithm (BFA), Bee's Algorithm (BA), Cat Algorithm, Ant Colony, Bat Algorithm, Bats Algorithm, Grey wolf optimization algorithm, Flower Pollination Algorithm, Harmony research (HS), whale optimization algorithm, Coronavirus and Particle Swarm Optimization (PSO), etc...) were studied [4], [5], [6]. Another category of PID controllers is the single neuron
PID that can be improved the dynamic response of the traditional PID controller [7]. The single neuron controller has the benefit of adaptive, self-learning, online adjustment, and relatively lower requirements for stability and precision of controlled objects [8]. Moreover, the structure of the single neuron PID controller is simple and reliable [9], [10].

Artificial Intelligence (AI) was developed with almost special attention to computational tasks that could be achieved offline based on accurate information about the problem being solved. The principle of control, on the other hand, is online performance in the presence of uncertainty. More recently, however, interest is increasing in AI systems that are situated, or embedded, in real environments in which uncertainty and time constraints play an important role [11]. Control principles are evolving as important assistants to AI methods. At the same time, researchers studying artificial neural networks are concentrating on control as a promising domain for practical applications as well as for its potential to further our understanding of biological control systems.

While most neural network algorithms are very closely connected to engineering methods, network research tends to continue the AI tradition of addressing problems that are not formulated with a high degree of mathematical structure [12].

Most engineering applications of artificial neural networks to adaptive control reported in the literature are the result of such substitutions. Although the theorems proven for conventional methods do not readily extend to most neural network controllers, this approach clearly 
shows how memory-intensive methods can extend conventional adaptive control methods. Perhaps a better understanding of how animals learn to control highly nonlinear systems under great uncertainty can provide guidance for the development of similarly effective engineering methods [13], [14].

In the beginning, the initial values of SNPID control parameters can be estimated by try and error and this takes a long time of the simulation. Now, the optimization techniques are used for tuning usually rely on the computation of a cost function representing the desired performance while satisfying the system constraints [15]. The weights adjusting method of SNPID control is highly affected on the control performance [12]. There are various weights-learning algorithms based on the learning theory of neural networks such as supervised delta learning rules, non-supervised Hebb learning rules, improved Hebb learning rule, and supervised Hebb learning rule [16], [17].

Sliding Mode Control (SMC) is mainly a nonlinear discontinuous control method, which uses a relay as the basic control element and can be used for robust control design [18]. The advantages presented by sliding mode control involve reduced-order dynamics, insensitivity to bounded disturbances, and uncertainties [19]. The most critical disadvantage of sliding mode control is the chattering, which is basically the high-frequency oscillation of the state trajectory around the sliding surface and leads to oscillation of system outputs around the reference values [20]. The possible causes of chattering include the presence of discontinuous switching terms in the derivative 3 of the sliding variable and the delay in switching [21].

Therefore, this paper treats the chattering problem for three different structures of SMC during the change of operating conditions of PSS. The transition between states will occur smoothly. Also, the performance of PSS will be enhanced. The FP optimization search is used to get the optimal values of SNPID parameters and the switching function of SMC. The SIMULINK MATLAB had been used to apply the combination of SNPID controller (main controller) and SMC as a self-tuning for the SNPID for PSS. The simulation results confirmed the efficiency of the suggested combined three controllers.

\section{Power System Stabilizer Model}

In the considered application a single machine infinite bus that comprises a voltage regulator and exciter are used. Figure 1 shows the block diagram of the linearized incremental model. Table 1 includes the parameters of the system [14], [15].

Different operating points under different disturbances with parameters variation are studied.

The normal, heavy, and light load conditions are noted the different operating points. The $\mathrm{K}$ is a row matrix computed and defined for each operating point. It is given as $\mathrm{K}=[\mathrm{K} 1, \ldots, \mathrm{K} 6]$. Table 2 . Gives these values of $\mathrm{K}$ under different operating points [16],[17].
Table 1. The parameters of the Power System Stabilizer

\begin{tabular}{cccc} 
& & & \\
Parameter & Value & Parameter & Value \\
& & & \\
\hline $\mathrm{Ka}$ & 400 & $\mathrm{D}$ & 0 \\
$\mathrm{Ta}$ & 0.05 & Efdmax & 7.3 \\
$\mathrm{Tdo}$ & 5.9 & Efdmin & -7.3 \\
$\mathrm{M}$ & 4.74 & umax & 0.12 \\
$\mathrm{Kf}$ & 0.025 & umin & -0.12 \\
$\mathrm{Tf}$ & 1 & & 0 \\
\hline
\end{tabular}

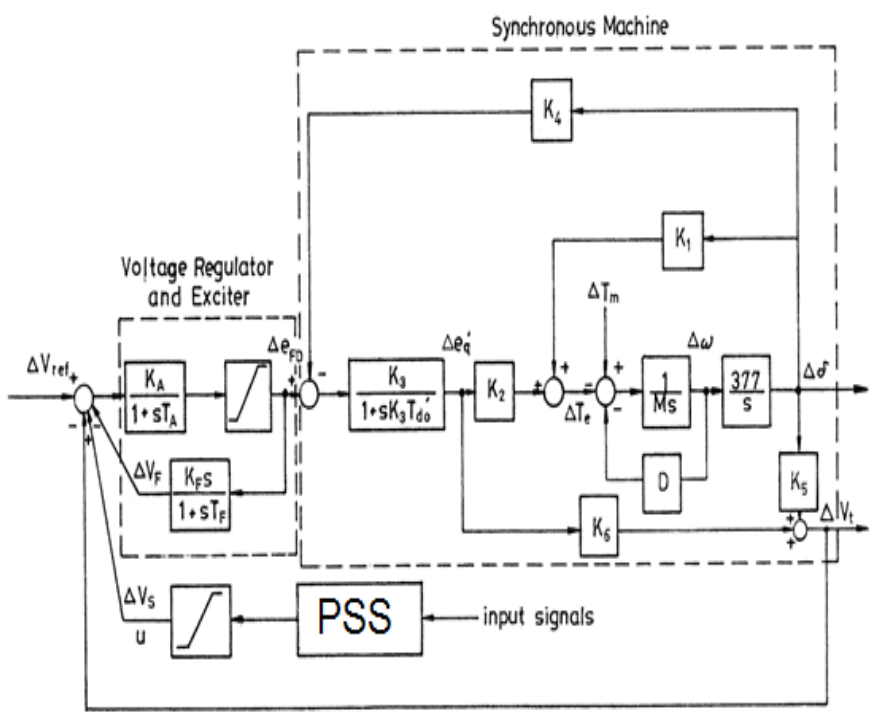

Fig. 1. A linearized incremental model of a synchronous machine with an exciter and stabilizer.

\section{Control Techniques}

This section shows the proposed combination controllers. The first part is a SNPID based on Flower pollination. The second one is the self-tuning of the SNPID controller based on optimal SMC to improve the performance of the controller outputs for PSS.

\subsection{Single Neuron PID Control}

The SNPID control is one of the simplest neural networks that imitate the PID controller and is based on only one neuron. The structure of the SNPID controller is illustrative in Figure 2. It can be noted that the signal converter transforms the error signal into three outputs which stand for the proportional, integral, and differential multipliers. Also, the weights adjusting block can tune the values of the weights to give high performance and satisfied dynamic response. Finally, the gain scheduling (k) compromises the output signal of the SNPID controller. 


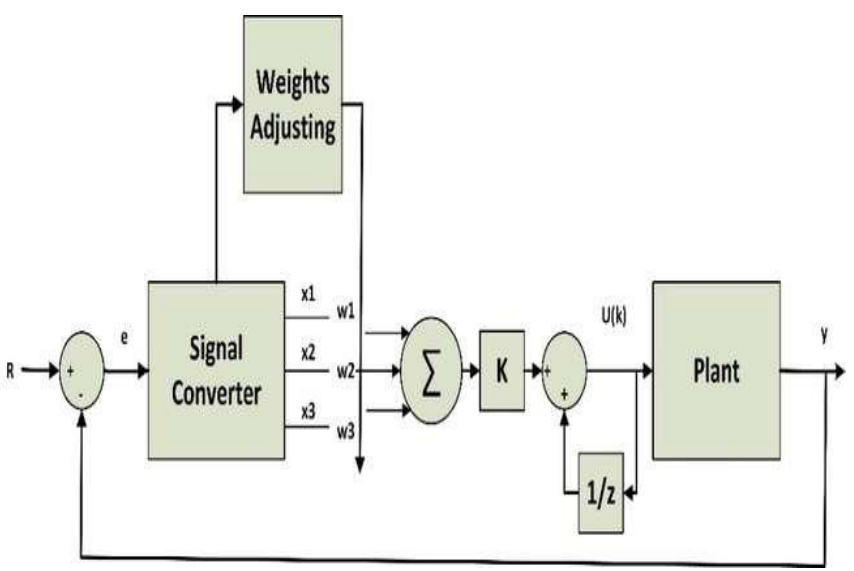

Fig. 2. The SNPID control structure.

Since the continuous-time traditional PID can be represented as:

$$
u(t)=k_{P} e(t)+k_{I} \int_{0}^{t} e(t) d t+k_{d} \frac{d e}{d t}
$$

Then, the output of the SNPID control is $u(t)$ and the loop error is $e$. The discretization can be performed by differentiating both sides of equation (1).

$$
u(t)=k_{P} e(t)+k_{I} e(t)+k_{d} \frac{d e}{d t}
$$

The backward differentiation method on equation (2)

$$
u(h)-u(h-1)=k_{P}[e(h)-e(h-1)]+
$$

$k_{I}[e(h)]+k_{d}[\dot{e}(h)-\dot{e}(h-1)]$

Applying the backward differentiation method again can give equation (4).

$$
\begin{aligned}
& u(h)-u(h-1)=k_{P}[e(h)-e(h-1)]+ \\
& k_{I}[e(h)]+k_{d}[e(h)-e(h-1)]-[e(h-1)- \\
& e(h-2))]
\end{aligned}
$$

Solving for $u(h)$ finally from equation (4) gives the discrete-time PID controller.

$$
\begin{gathered}
u(h)=u(h-1)+k_{P}[e(h)-e(h-1)]+ \\
k_{I}[e(h)]+k_{d}[e(h)-2 e(h-1)+e(h-2)]
\end{gathered}
$$

Then, $u(h)=u(h-1)+k_{P}\left[x_{1}(h)\right]+k_{I}\left[x_{2}(h)\right]+$ $k_{d}\left[x_{3}(h)\right]$

Let us consider that

$$
\begin{aligned}
& x_{1}(h)=e(h)-e(h-1) \\
& x_{2}(h)=e(h) \\
& x_{3}(h)=e(h)-2 e(h-1)+e(h-2)
\end{aligned}
$$

Where $x_{1}(h)$ is a proportional error, $x_{2}(h)$ is an integral error and $x_{3}(h)$ is a differential error.

The SNPID controller can be expressed as:

$$
\begin{aligned}
& u(h)=u(h-1)+K \Sigma \overline{w_{l}}(h) x_{i}(h) \\
& \overline{w_{l}}(h)=w_{i}(h) / \Sigma\left|w_{i}(h)\right|
\end{aligned}
$$

Where $u(h)$ is the controller output and $w_{1}(\mathrm{~h}), w_{2}(h)$ and $w_{3}(h)$ are the neuron weights. $K$ is the proportion coefficient of neurons. There are various weights learning algorithms based on the learning theory of neural networks and the famous algorithm that is used in this work is the supervised Hebb learning rule which can be given as [9].

$$
\begin{gathered}
w_{1}(\mathrm{~h})=w_{1}(\mathrm{~h}-1)+\eta_{p} x_{1}(\mathrm{~h}-1) \mathrm{u}(\mathrm{h}-1) \mathrm{e}(\mathrm{h}-1) \\
w_{2}(\mathrm{~h})=w_{2}(\mathrm{~h}-1)+\eta_{i} x_{2}(\mathrm{~h}-1) \mathrm{u}(\mathrm{h}-1) \mathrm{e}(\mathrm{h}-1) \\
w_{3}(\mathrm{~h})=w_{3}(\mathrm{~h}-1)+\eta_{d} x_{3}(\mathrm{~h}-1) \mathrm{u}(\mathrm{h}-1) \mathrm{e}(\mathrm{h}-
\end{gathered}
$$

Where $e$ is the error, $\eta_{p}, \eta_{i}$ and $\eta_{d}$ are the proportion learning speed, the integral learning speed, and the differential learning speed respectively. Also, $w_{1}(\mathrm{~h}-$ $1), w_{2}(\mathrm{~h}-1)$ and $w_{3}(\mathrm{~h}-1)$ are the initial values of neuron weights, which consider unknown parameters [22], [17].

\subsection{Sliding Mode Control}

SMC has been implemented in many successful engineering applications. For instance, the power electronics applications have been applied successfully using the SMC. Also, the SMC considers one of the types of non-linear controllers which is described as accuracy, high performance, robustness, easy tuning its parameters, and implementation.

SMC systems are established to force the system states to follow a specific surface in the state space, named sliding surface. Once the sliding surface is touched, sliding mode control retains the states on the close neighborhood of the sliding surface. Hence the sliding mode control needs two steps to complete the controller design. The first step excludes the design of a sliding surface so that the sliding motion accomplishes the required performance. The second step is interested in the choice of a control law that will make the transferring surface attractive to the system state [23], [24].

The main benefits of sliding mode control can be summarized into two categories. The first is that the dynamic behavior of the system may be adjusted by the private selection of the sliding function. Secondly, the closed-loop response converts completely unaffected to some types of uncertainties. This principle shields to model parameter uncertainties, disturbance, and nonlinearity that are bounded. From a practical point of view SMC permits for controlling nonlinear processes subject to external disturbances and heavy model uncertainties. Sometimes, the SMC outputs suffer from shuttering which can cause several problems through the practical implementation [25], [26].

Assume the nonlinear SISO system;

$$
\begin{gathered}
\dot{x}=f(x, t)+g(x, t) u \\
y=W(x, t)
\end{gathered}
$$

Where $y$ and $u$ stand for the scalar output and input variable, $x \in R^{n}$ and represents the state vector. SMC combines two phases [20]. 
The first phase is sliding surface design. The second phase is the control input design. The first phase is the description of a certain scalar function of the system state, says $\sigma(x): R^{n} \rightarrow R$ Usually, the sliding surface depends on the tracking error $e$ together with a certain number of its derivatives.

$$
\sigma=\sigma\left(e, \dot{e}, \ldots \ldots \ldots, e^{(k)}\right)
$$

The function $\sigma$ has to select in such a way that accommodates itself, $\sigma=0$ gives rise to a "stable" differential equation any solution $e(t)$ of which will tend to zero eventually. The most typical choice for the sliding manifold is a linear combination of the following type:

$$
\begin{gathered}
\sigma=\dot{e}+c_{0} e \\
\sigma=\ddot{e}+c_{1} \dot{e}+c_{0} e \\
\sigma=e^{(k)}+\sum_{i=0}^{k-1} c_{i} . e^{i}
\end{gathered}
$$

The number of derivatives to be contained within (the " $\mathrm{k}$ " coefficient in (16)) should be $k=r-1$, where $r$ is the input/output relation degree. With correctly nominated $c_{i}$ coefficients, if one directs to zero the $\sigma$ variable, the exponential disappearing of the error and its derivatives are obtained. If such property holds, then the control goal is to provide for the finite time zeroing of $\sigma$, "forgetting" any other aspects. In this paper, a typical form for the sliding surface in equation (15) depends on just a single scalar parameter, $\mathrm{p}$.

$$
\begin{aligned}
& c_{0}=\mathrm{p}^{2} \\
& c_{1}=2 \mathrm{p}
\end{aligned}
$$

From a geometrical point of view, the equation $\sigma=0$ defines a surface in the error space, which is called "sliding surface". The trajectories of the controlled system are forced onto the sliding surface, along which the system behavior meets the design specifications.

The choice of the positive parameter $p$ is almost random and defines the unique pole of the resulting "reduced dynamics" of the system when in sliding. The integer parameter $k$ is on the contrary rather critical, it must be equal to $r-1$, with $r$ being the relative degree between $\mathrm{y}$ and $\mathrm{u}$. This means that the relative degree of the $\sigma$ variable is one. The successive phase (PHASE 2) is finding a control action that steers the system trajectories onto the sliding manifold, that is, in other words, the control is able to steer the $\sigma$ variable to zero in finite time.

A common feature of all sliding model-based techniques is that no precise information about the original system dynamics is requested, the controlled system is treated as a completely uncertain "black box" object.

There are several approaches based on the sliding mode control approach. Three different structures of SMC are considered in this work:

The first structure is:

$$
\begin{aligned}
& \quad u=-U \cdot \operatorname{sgn}(\sigma) \\
& \text { That is } \\
& u=\left\{\begin{array}{cc}
-U & \sigma>0 \\
U & \sigma<0
\end{array}\right\}
\end{aligned}
$$

$\mathrm{U}$ is a sufficiently large positive constant. In a steady state the control variable, $\mathrm{u}$ will commute at a very high (theoretically infinite) frequency between the values $\mathrm{u}=$ $\mathrm{U}$ and $\mathrm{u}=-\mathrm{U}$ (see Figure 3)

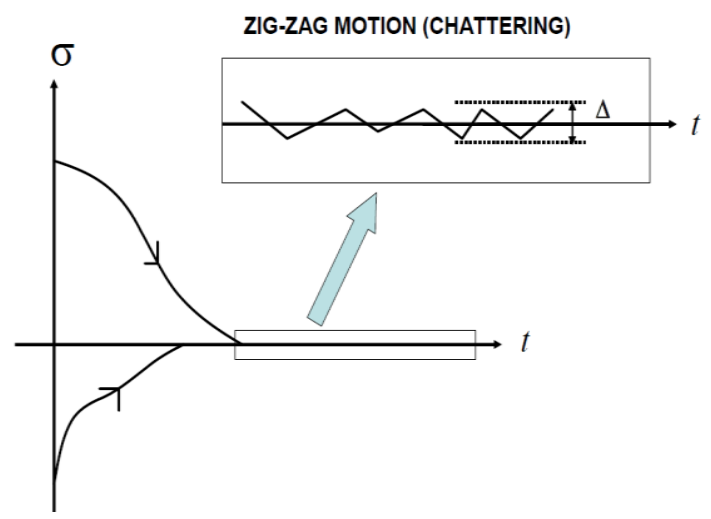

Fig. 3. Typical evolution of the $\sigma$ variable starting from different initial conditions.

The discontinuous high-frequency switching control gives rise to oscillations and many problems in different areas like, e.g., the control of mechanical systems. In order to solve the above problem (referred to as "chattering phenomenon") approximate (smoothed) implementations of sliding mode control techniques have been suggested where the discontinuous "sign" term is replaced by a continuous smooth approximation.

The second structure is

$$
u=-U \operatorname{sat}(\sigma ; \varepsilon) \equiv-U \frac{\sigma}{|\sigma|+\varepsilon} \quad \varepsilon>0, \varepsilon \approx 0
$$

The third structure is

$$
u=-U \tanh \left(\frac{\sigma}{\varepsilon}\right) \quad \varepsilon>0, \varepsilon \approx 0
$$

Unfortunately, this approach is effective only in a specific case, the is when hard uncertainties are not present and the control action that counteracts them can be set to zero in the sliding mode.

\subsection{Sliding Mode Control Based Single Neuron PID Strategy (SMC-SNPID)}

This section presents a novel technique that combines the SNPID strategy and the SMC. The SNPID control is used to improve the performance of PSS, while the SMC is used to move the sliding surface and further reduce the effect of the change in operating point.

Figure 4 demonstrates the blocking scheme of adaptive sliding mode control based on the SNPID strategy. It is known that the standard (or first-order) sliding mode control, control is discontinuous across the manifold $\sigma=0$. 


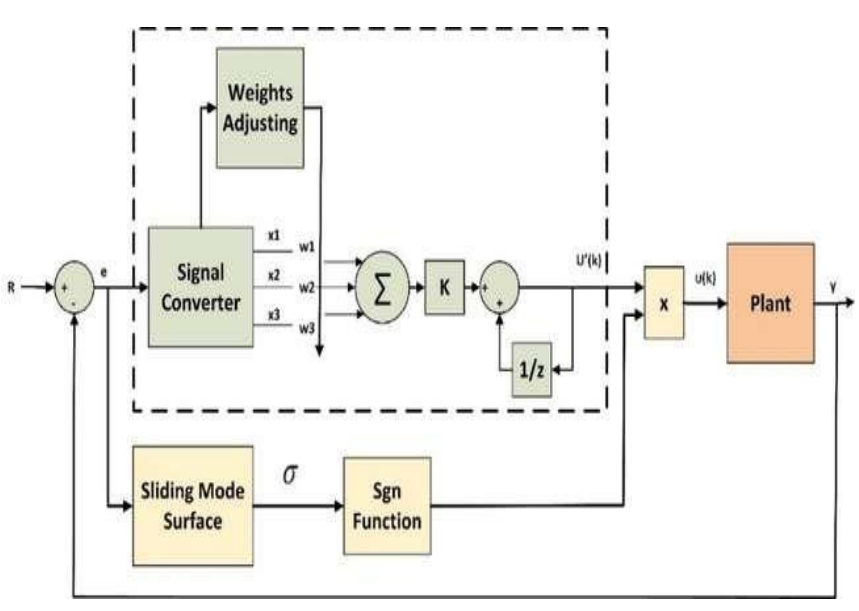

Fig. 4. Block scheme of adaptive sliding mode control based SNPID strategy.

The adaptation law of $U^{\prime}(h)$ depends on the SNPID strategy as demonstrated in equation (23).

$U^{\prime}(h)=U^{\prime}(h-1)+K\left[\overline{w_{1}}(h) \cdot x_{1}(h)+\right.$

$\left.\overline{w_{2}}(h) \cdot x_{2}(h)+\overline{w_{3}}(h) \cdot x_{3}(h)\right]$

Where:

$$
\begin{gathered}
\overline{w_{1}}(h)=\frac{w_{1}(h)}{\left|w_{1}(h)+w_{2}(h)+w_{3}(h)\right|} \\
\overline{w_{2}}(h)=\frac{w_{2}(h)}{\left|w_{1}(h)+w_{2}(h)+w_{3}(\mathrm{~h})\right|} \\
\overline{w_{3}}(h)=\frac{w_{3}(h)}{\left|w_{1}(h)+w_{2}(h)+w_{3}(h)\right|}
\end{gathered}
$$

Where $x_{1}(h)$ is a proportional error, $x_{2}(h)$ is an integral error and $x_{3}(h)$ is a differential error.

\subsection{The Flower Pollination (FP)}

In nature, the main purpose of flower pollination is the existence of the fittest and an optimal duplicate of flowering plants. Pollination in flowering plants can take two major forms, i.e. biotic and abiotic [22]. About 90\% of flowering plants belong to biotic pollination. Pollen is transferred by a pollinator such as bees, birds, insects, and animals About $10 \%$ remaining of pollination takes abiotic such as wind and diffusion in water. Pollination can be achieved by self-pollination or cross-pollination. Self-pollination is the fertilization of one flower from the pollen of the same flower (Autogamy) or different flowers of the

same plant (Geitonogamy). They occur when the flower contains both male and female gametes. Selfpollination usually occurs at short distances without pollinators. It is regarded as local pollination. Crosspollination, Allogamy, occurs when pollen grains are moved to a flower from another plant. The process happens with the help of biotic or abiotic agents as pollinators. Biotic, cross-pollination may occur at a long distance with biotic pollinators. It is regarded as global pollination. Bees and birds as biotic pollinators behave Lévy flight behavior [27] with jump or fly distance steps obeying a Lévy distribution. The FPA algorithm was proposed by Yang [28].
The FP optimization has been used to estimate the optimal values for the seven parameters that are important in the design of the SNPID control, these parameters are $k, \eta_{P}, \eta_{I}, \eta_{D}, w_{1}(\mathrm{~h}-1), w_{2}(\mathrm{~h}-1)$ and

$w_{3}(\mathrm{~h}-1)$. The used performance index for this purpose is as follows equation (27).

$$
f=\frac{1}{\left(1-e^{-\beta}\right)\left(M_{p}+e_{s s}\right)+e^{-\beta}\left(t_{s}-t_{r}\right)}
$$

The actual closed-loop specification of the system with controller, rise time $\left(t_{r}\right)$, maximum overshoot $\left(M_{p}\right)$, settling time $\left(t_{s}\right)$, and steady-state error $\left(e_{s s}\right)$. This objective function can satisfy the designer's requirement using the weighting factor value $(\beta)$. The factor is set larger than 0.7 to reduce overshoot and steady-state error. If this factor is set smaller than 0.7 the rise time and settling time will be reduced [22], [24].

Table 2, 3, 4 illustrates the calculated optimal values of the tuned SMC - SNPID - using cost function given by equation (27).

Table 2. The obtained SMC (Sgn- Function) - SNPID'S controller parameters optimized by FP.

\begin{tabular}{lllllllll}
\hline$\Delta \mathbf{V}$ & $\Delta \mathbf{T}$ & $\mathbf{K}$ & $\mathbf{\eta p}$ & $\mathbf{\eta i}$ & $\mathbf{\eta d}$ & $\boldsymbol{w}_{\mathbf{1}}$ & $\boldsymbol{w}_{\mathbf{2}}$ & $\boldsymbol{w}_{\mathbf{3}}$ \\
\hline 0.05 & 0.05 & 92 & 0.8 & 0.878 & 0.98 & 0.001 & 0.001 & 0.001 \\
\hline
\end{tabular}

Table 4. The obtained SMC (Tanh- Function) - SNPID'S controller parameters optimized by FP.

\begin{tabular}{llllllccc}
\hline$\Delta \mathbf{V}$ & $\Delta \mathbf{T}$ & $\mathbf{K}$ & $\boldsymbol{\eta p}$ & $\mathbf{\eta} \mathbf{i}$ & $\mathbf{\eta d}$ & $\boldsymbol{w}_{\mathbf{1}}$ & $\boldsymbol{w}_{\mathbf{2}}$ & $\boldsymbol{w}_{\mathbf{3}}$ \\
\hline 0.05 & 0.05 & 90.98 & 0.789 & 0.778 & 0.8897 & 0.001 & 0.001 & 0.001 \\
\hline
\end{tabular}

Table 5. The obtained SMC (o /ơ + e) Function SNPID'S controller parameters optimized by FP.

\begin{tabular}{lllllllll}
\hline$\Delta \mathbf{V}$ & $\Delta \mathbf{T}$ & $\mathbf{K}$ & $\boldsymbol{\eta p}$ & $\boldsymbol{\eta} \mathbf{i}$ & $\mathbf{\eta d}$ & $\boldsymbol{w}_{\mathbf{1}}$ & $\boldsymbol{w}_{\mathbf{2}}$ & $\boldsymbol{w}_{\mathbf{3}}$ \\
\hline 0.05 & 0.05 & 40 & 0.745 & 0.456 & 0.567 & 0.001 & 0.001 & 0.001 \\
\hline
\end{tabular}

Figure 5 demonstrates the SNPID -SMC controllers output with and without shuttering at different values of $\mathrm{P}$. It can note that the value of the $\mathrm{P}$ parameter obtained by optimization $(\mathrm{P}=0.00645)$ is based on the cost function equation (28) can reduce the shuttering effect of SMC.

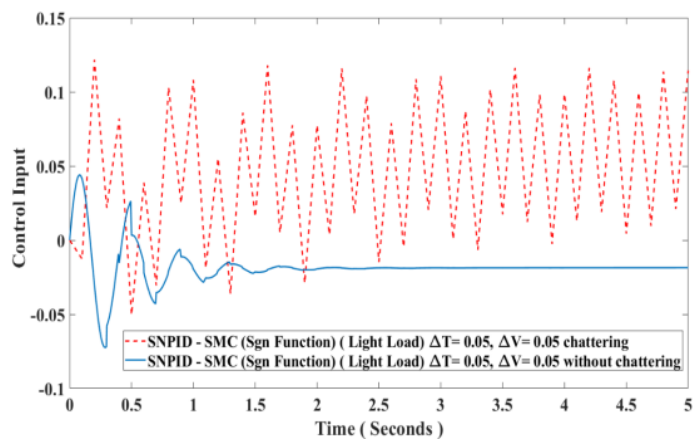

Fig. 5. The controller's output with and without shuttering. 


\section{The Simulation Results}

Several types of disturbances are performed to PSS of a single machine to investigate the effectiveness of combination between the self-tuning for SNPID based on SMC for different operating points through several types of disturbances, uncertainty parameters effects are also shown and given. The proposed controllers are investigated by applying the dynamic responses of the PSS to step disturbance $5 \%$ in mechanical torque $\Delta \mathrm{Tm}$ and $\Delta$ Vref for case one to four.

\section{Case 1: SNPID Controller performance at different operating conditions}

SNPID response has a better performance in a normal operating which the parameters of SNPID have optimized in this case as shown in Figures 6 (a), Figures 6 (b), and Figures 6 (c). But, the response in light and heavy operating conditions has a maximum overshoot and large steady-state error. So, self-tuning becomes essential to obtain high performance through several operating conditions and disturbances.

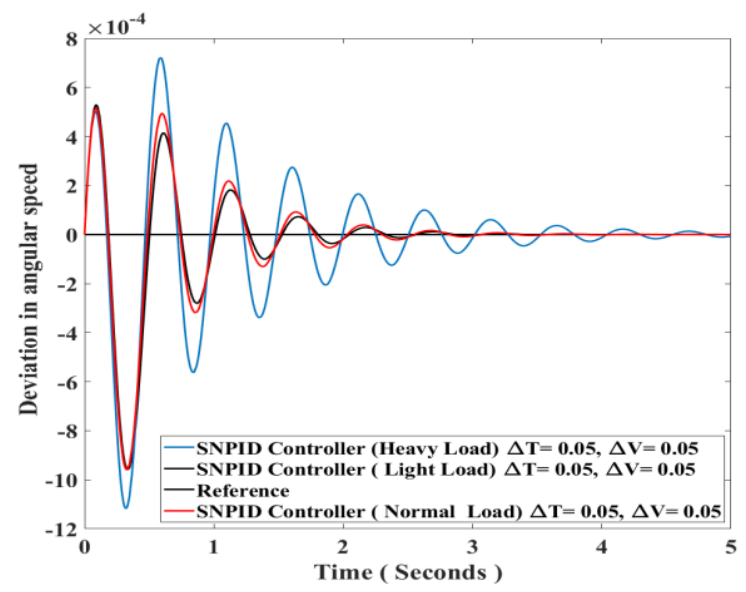

(a) Deviation in angular speed response

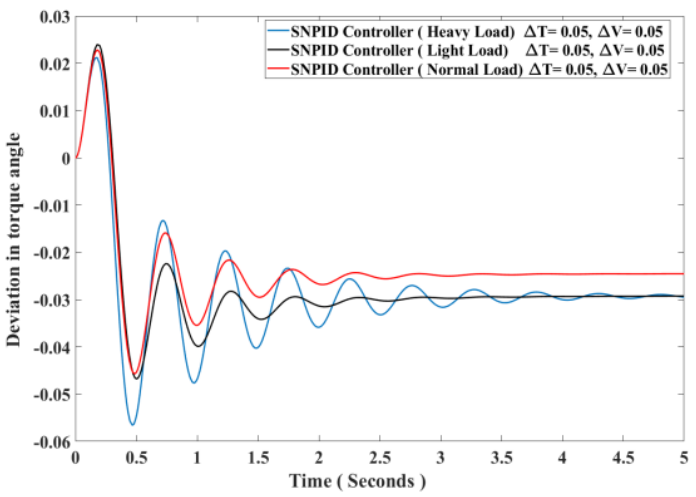

(b) Deviation in torque angle response

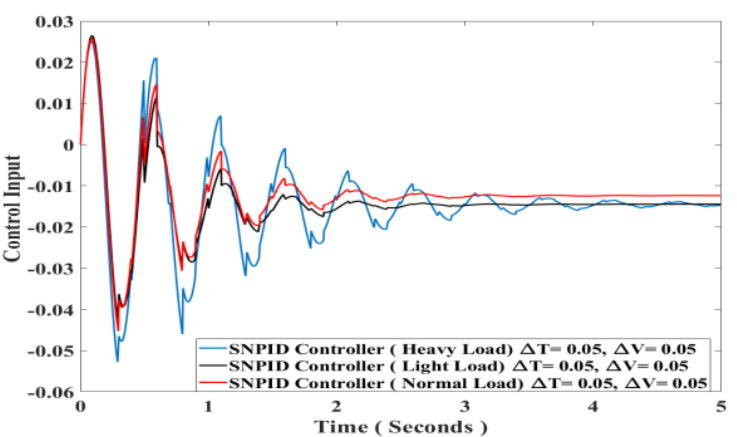

(c) Control input response.

Fig. 6. The system dynamic response with step-change 0.05 case 1 .

\section{Case 2: Comparison between the SNPID and ( SNPID - SMC ) at light load condition}

Figures 7 (a), Figures 7 (b), and Figures 7 (c) illustrate the results of this case. It is obvious that the dynamic response of SNPID - SMC (o /ơ e ) has a good performance compared to the SNPID controller where it has a smaller overshoot and small settling time.

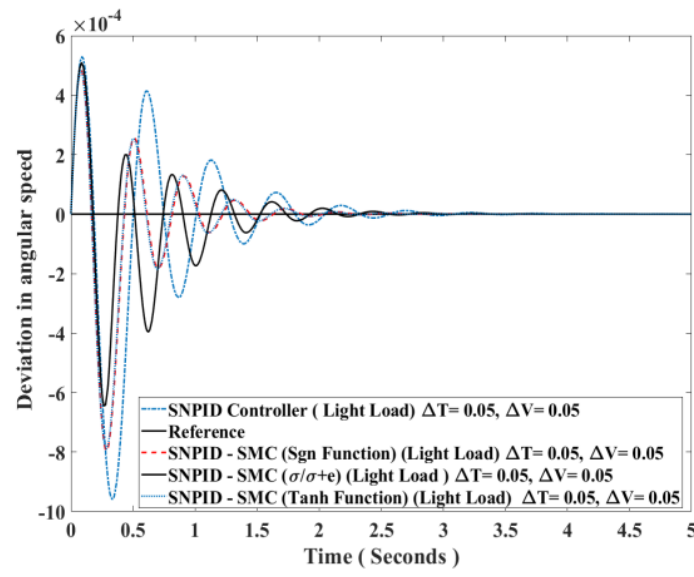

(a) Deviation in angular speed response

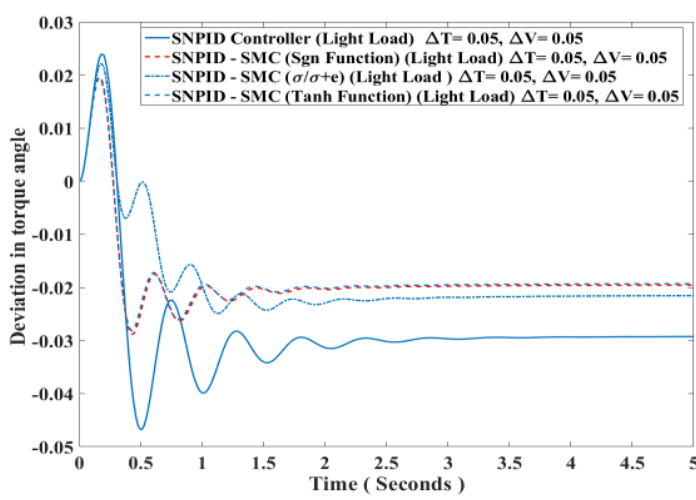

(b) Deviation in torque angle response 


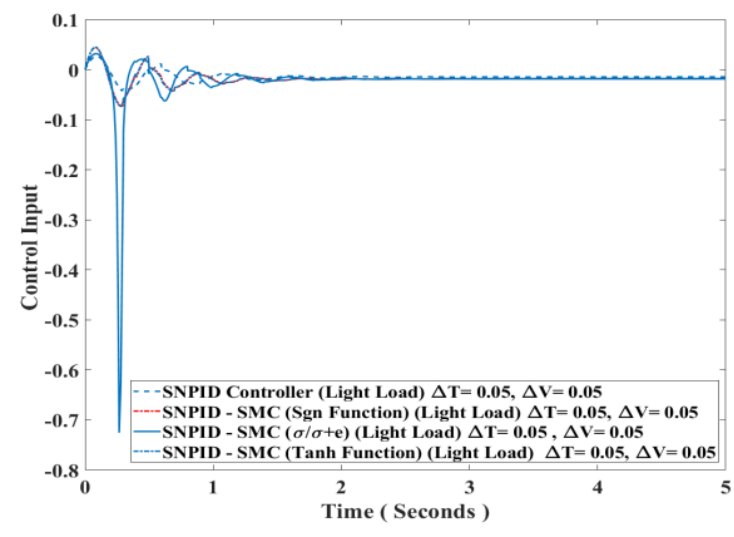

(c) Control input response.

Fig. 7. The system dynamic response with step change 0.05 case 2 .

\section{Case 3: Comparison between the SNPID and SNPID- Sliding mode control performance at heavy conditions.}

From the simulation results shown in Figures 8 (a), Figures 8 (b) and Figures 8 (c) it is noted that SNPID driven by SMC $(\sigma / \sigma+e)$ has the best responses with the fewest oscillations and minimum settling time than the other SMC types. In addition, the controller input response has low fluctuations, small overshoot and it reaches to reference point in a small time with SMC ( ( o / ơ $+\mathrm{e}))$.

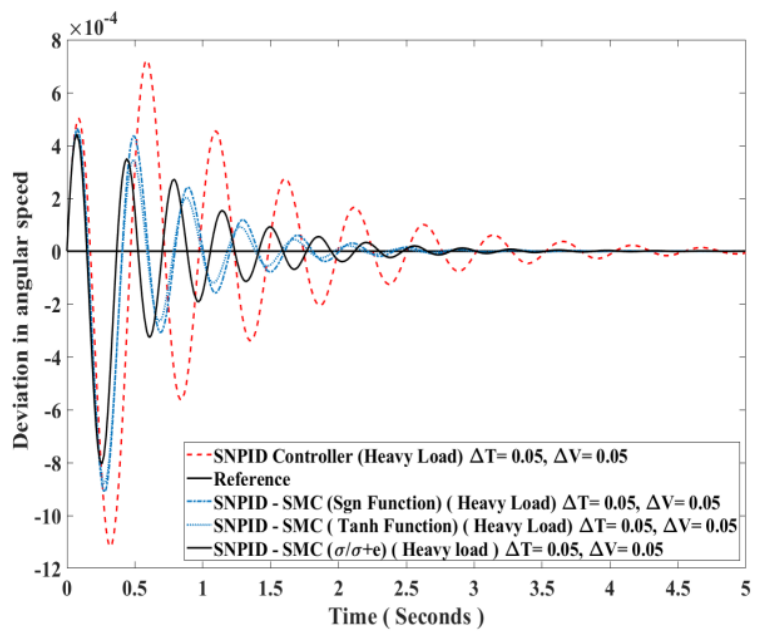

(a) Deviation in angular speed response,

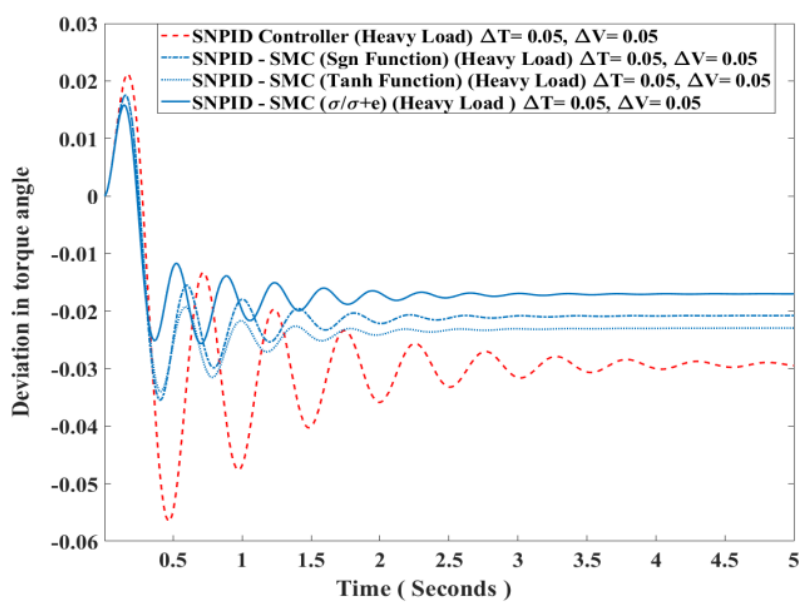

(b) Deviation in torque angle response

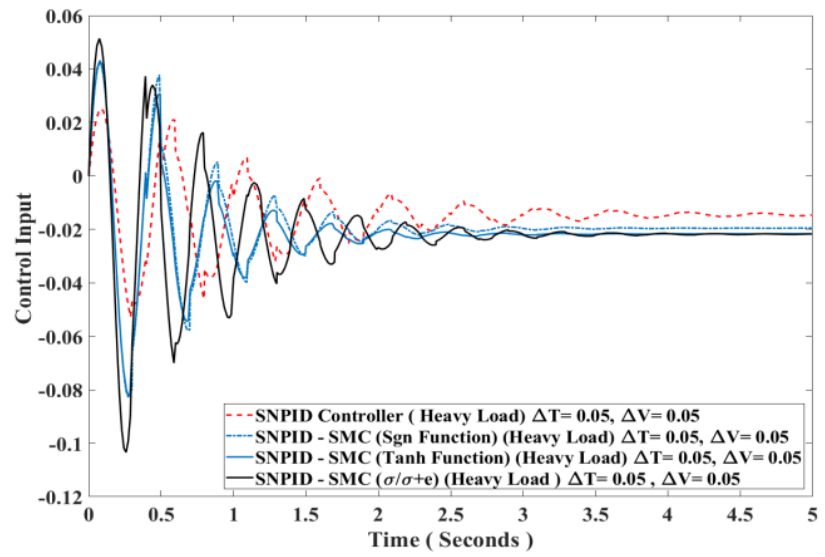

(c) Control input response

Fig. 8. The system dynamic response with step change 0.05 case 3 .

\section{Case 4: Comparison between the SNPIFD and self-tuning Sliding mode control performance at light condition through Tracking-response}

The disturbance for $\Delta \mathrm{Tm}$ and $\Delta$ Vref represented by a 0.05 step change from zero to 2 seconds, then, decreased by 0.03 from 2 seconds to 4 seconds and finally decreased by 0.01 as shown in Figures 9 (a), Figures 9 (b), Figures 9 (c) and Figures 9 (d). Also, Figure9 shows the system responses driven by self-tuning SMC (o /ơ+e ) and SNPID controller. It is clearly seen that the selftuning SMC (o /o+ e ) overcomes these variations and give a good response with a small settling time, thus indicating the effectiveness of the self-tuning Sliding mode control (o /o + e ) over a wide range of parameter variation and change of operating conditions. 
While self-tuning SMC for sign function and tanh function controller has large undershoot with a longer settling time. The control input for the self-tuning SMC $(o / o+e)$ controllers give a satisfactory result.

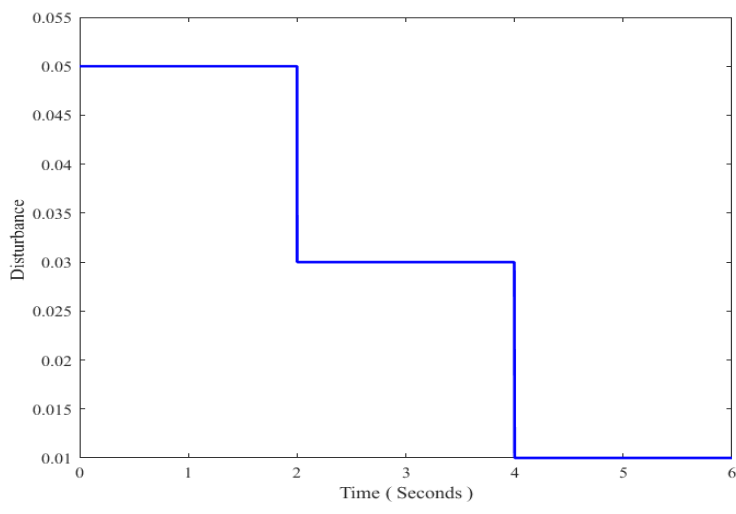

(a) Disturbance

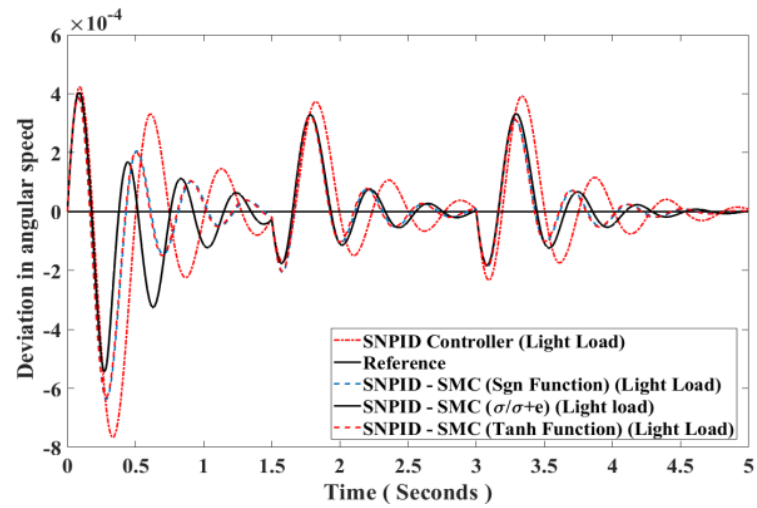

(b) Deviation in angular speed response.

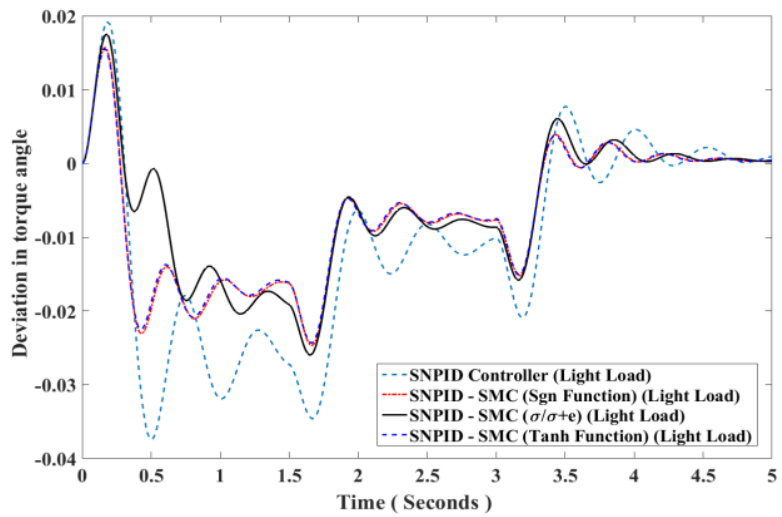

(c) Deviation in torque angle response)

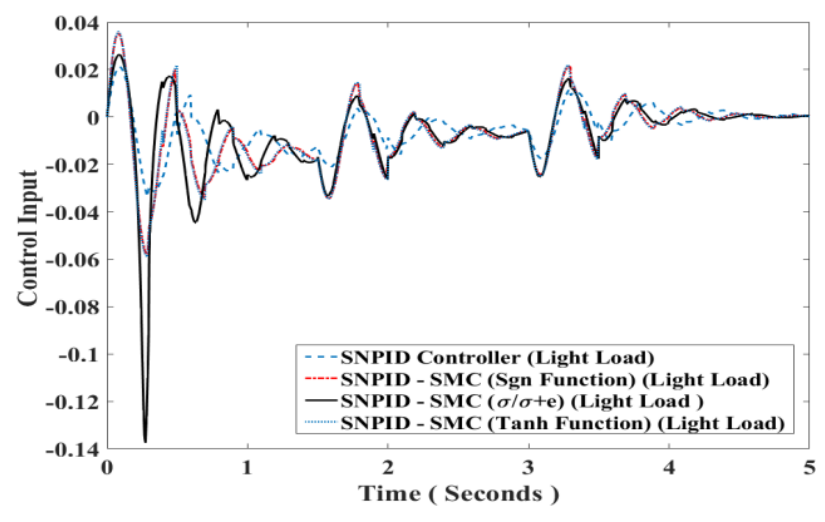

(d) Control input response.

Fig. 9. System dynamic responses with reference tracking case 4.

\section{Case 5: Comparison between the SNPIFD and self-tuning Sliding mode control performance at heavy conditions through Tracking-response}

The disturbance for $\Delta \mathrm{Tm}$ and $\Delta$ Vref implanted on case 4 is repeated in this case and shown in Figures 10 (a), Figures 10 (b), Figures 10 (c), and Figures 10 (d). The system responses of SNPID controller and its selftuning by SMC (ơ /ơ e ) clearly seen overcome these variations and give a good response with a small settling time, thus indicating the effectiveness of the self-tuning SMC ( $\circ / \mathrm{o}+\mathrm{e}$ ) over a wide range of parameter variation and change of operating conditions.

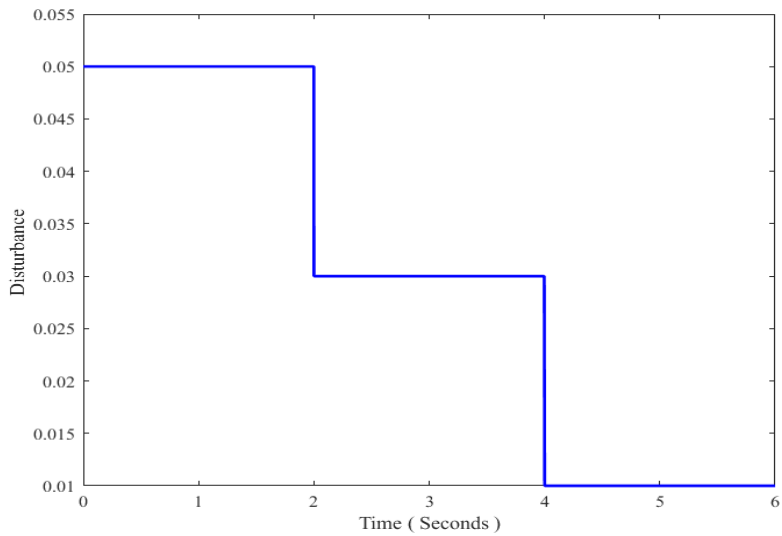

(a) Disturbance 


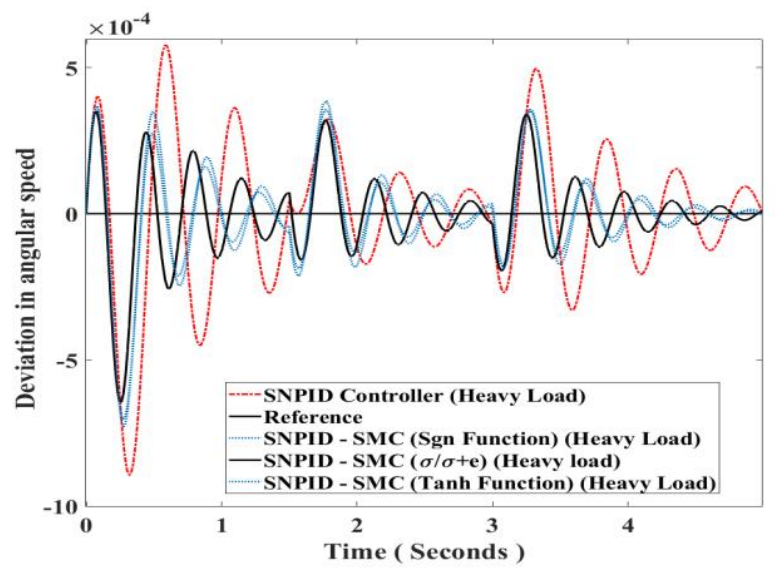

(b) Deviation in angular speed response

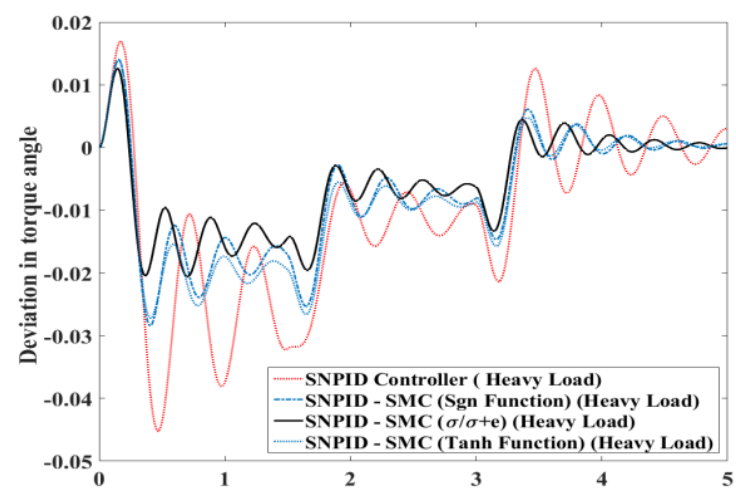

(c) Deviation in torque angle response

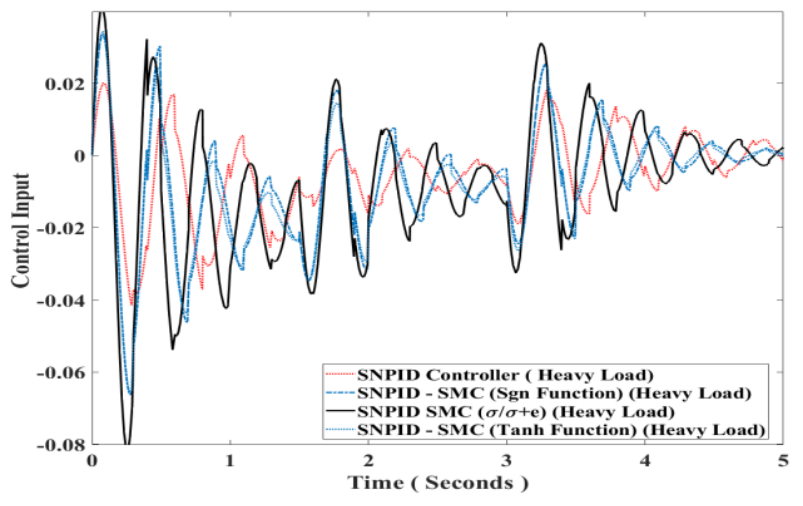

(d) Control input response.

Fig. 10. System dynamic responses with reference tracking case 5 .
Case 6: The performance of the SNPID and self-tuning sliding mode control during the parameters variations and Normal load condition.

To investigate the robustness of proposed controllers, the inertia coefficient increased to become $M=1.5$ of normal value, and the disturbance for $\Delta T m$ and $\Delta \mathrm{V}$ ref is given by Figures 11 (a), Figures 11 (b), Figures 11 (c), and Figures 11 (d). Over a wide range of parameter variation and change of PSS operating conditions SNPID controller that combined with the selftuning SMC (o /o+e ) as shown in Figure 11 overcomes these variations and give a better response with a small settling time, thus indicating the effectiveness of the selftuning SMC (o /o+ e ) than the other structure of SMC.

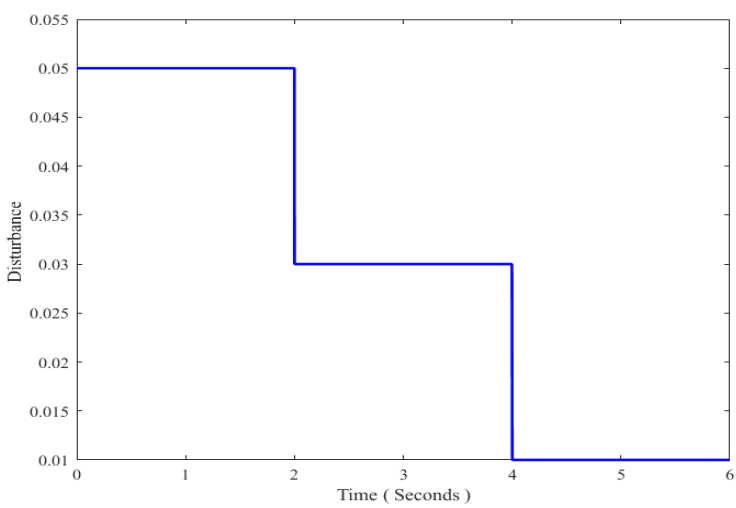

(a) Disturbance

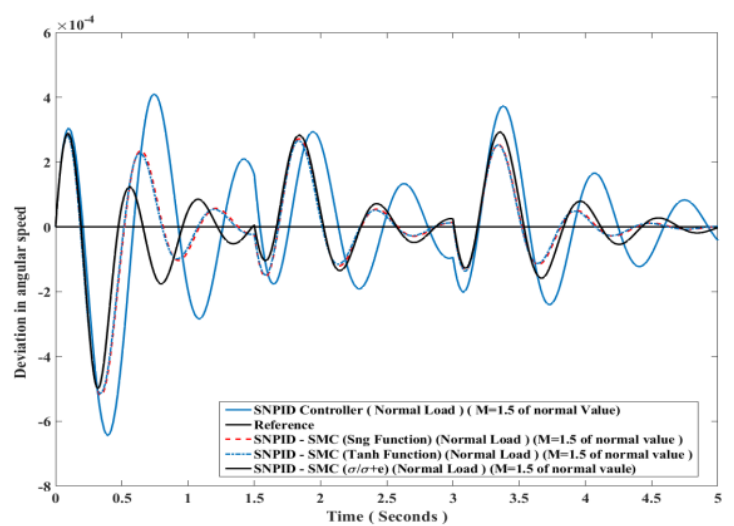

(b) Deviation in angular speed response 


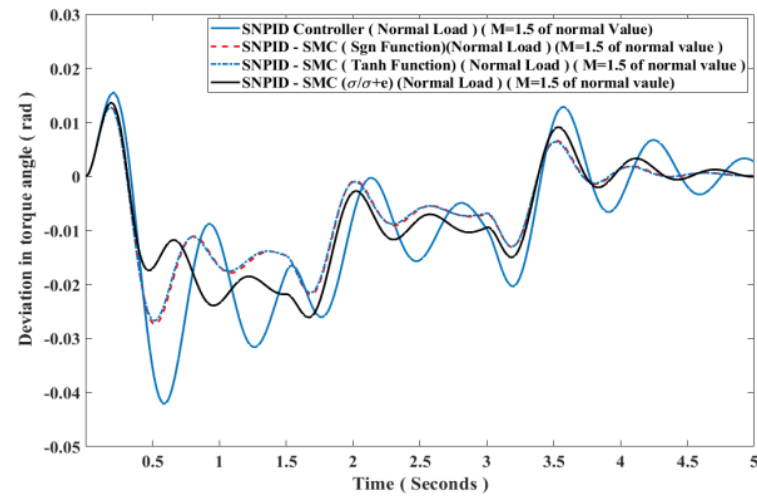

(c) Deviation in torque angle response

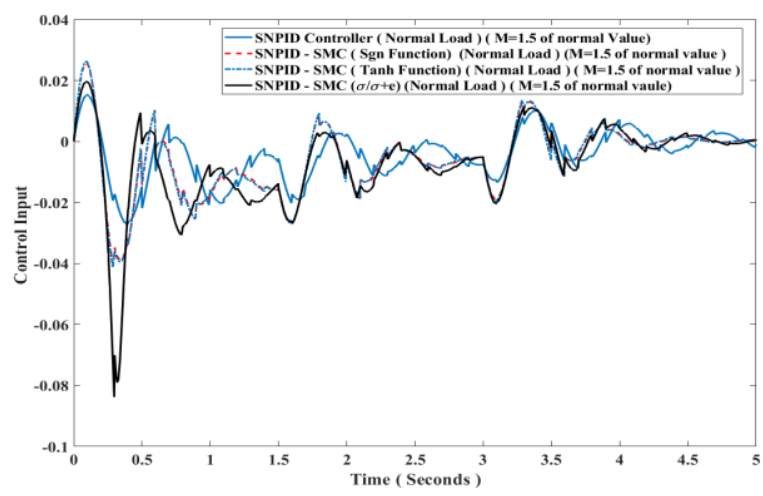

(d) Control input response

Fig. 11. System dynamic responses with reference tracking case 6 .

\section{Case 7: The performance through Uncertainty in Parameters as shown in table 6}

In this test, a comparison between the system driven by SNPID and SNPID - SMC at step disturbance 5\% in the mechanical torque $\Delta \mathrm{Tm}$ and $\Delta$ Vref during system parameter uncertainty. The system is operated by the PSS with (Light operating). The parameters are changed as follows: from $0-2$ (15\% Value), 2-4 (-15\% Value), 4-5 (Normal Value), as shown in Table 5 and Figure16. The time response of the deviation in angular speed, deviation in torque angle, and the control input are shown in Figures 12 (a), Figures 12 (b), Figures 12 (c), and Figures 12 (d). Again, the proposed controller SNPID - SMC $(\% / \%+e)$ shows a great improvement in the system than the other two with fewer overshoots and shorter settling times. The control input shows less effort made as compared to the other two.
Table 5. The deviation in Parameters.

\begin{tabular}{cccc}
\hline parameters & $\begin{array}{c}\text { Normal } \\
\text { Value }\end{array}$ & $\begin{array}{c}\text { Increase 15 } \\
\text { \% }\end{array}$ & $\begin{array}{c}\text { Decrease } \\
\mathbf{1 5} \%\end{array}$ \\
\hline $\mathrm{M}$ & 4.74 & 5.451 & 4.029 \\
$\mathrm{Td}$ & 5.9 & 6.785 & 5.015 \\
$\mathrm{Ka}$ & 400 & 460 & 340 \\
\hline
\end{tabular}

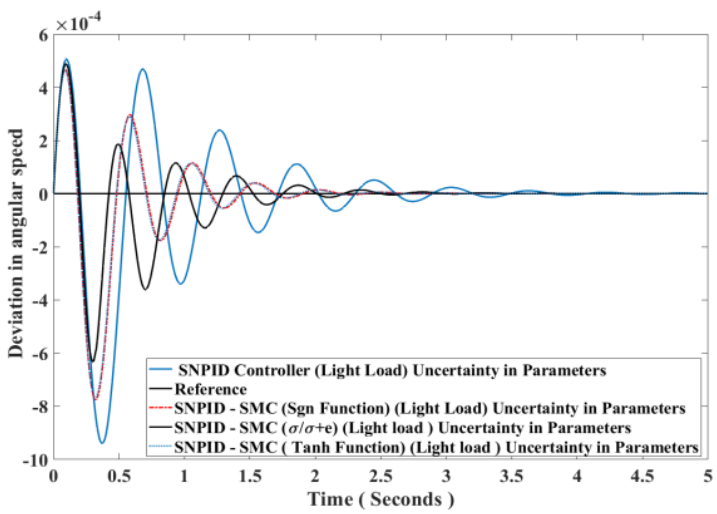

(a) Deviation in angular speed response.

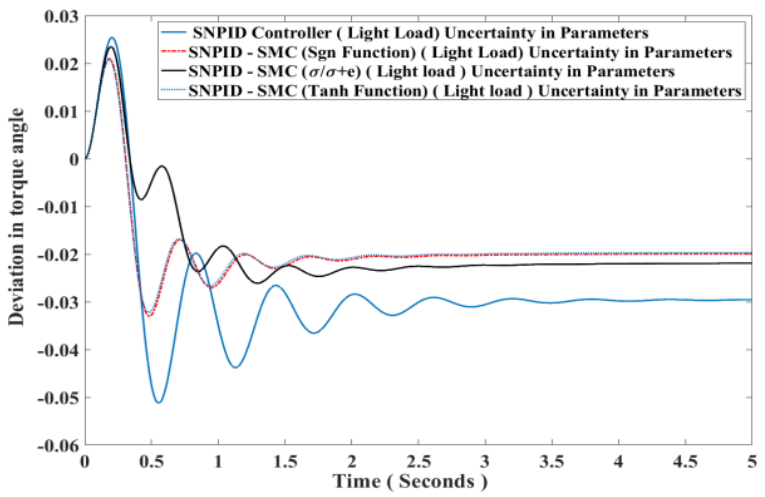

(b) Deviation in torque angle response.

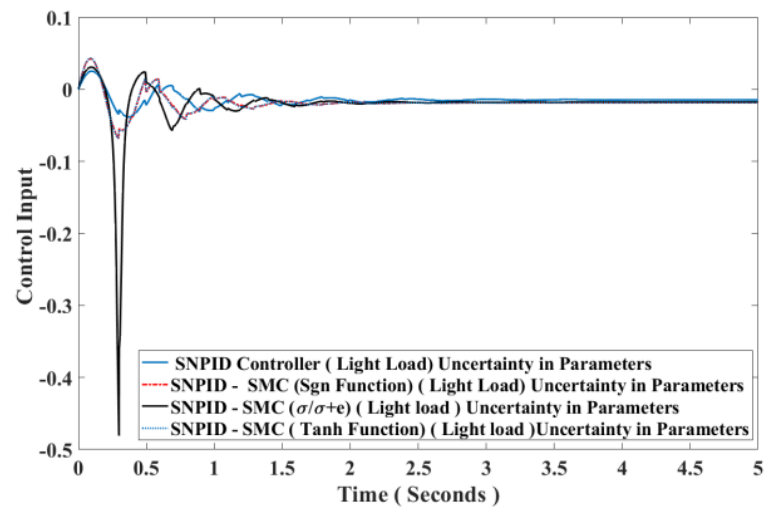

(c) Control input response and uncertainty parameters curve. 


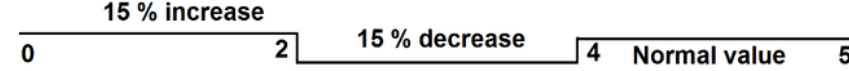

(d) Disturbance.

Fig. 12. System dynamic responses with uncertainty parameters case 6 .

\section{Conclusion:}

This paper presents a new combination of Single Neuron PID- and Sliding Mode Control (SNPID-SMC) to propose a modified robust controller. The proposed controller had been subjected to Power System Stabilizer (PSS). The objective of SNPID is to adapt the sliding surface online to increase the robustness against the disturbances and the change of operating point of PSS. Therefore, several operating points of PSS had been applied to investigate the effectiveness of the SNPIDSMC controller. The application of Flower pollination has been presented to determine the optimum values of SNPID training parameters and switching function of SMC. In addition, different structures of SMC had implemented and merged with SNPID control to obtain the best performance of PSS. It is clear that chattering is reduced by proper selection of the switching function using the Flower pollination optimization algorithm. The effectiveness of the proposed SNPID-SMC is shown through diverse tests namely, severe disturbances and uncertainty parameter changes. The system equipped with SNPID-SMC (o/ o+ e) shows smooth behavior and robustness to severe disturbances, less sensitivity with change in the operating points, and uncertainty of parameters variation.

\section{References:}

[1] S. Dewangan, S. Ramani, and M. T. Scholar, "A Comparison of Artificial Bee Colony Based FOPID and PID for SMIB System," Int. J. Eng. Dev. Res., vol. 5, no. 3, pp. 728-731, 2017.

[2] S. Bhattacharya, "Power system oscillation damping by intelligent power system stabilizer," 1st IEEE Int. Conf. Power Electron. Intell. Control Energy Syst. ICPEICES 2016, 2017, doi: 10.1109/ICPEICES.2016.7853509.

[3] S. Keskes, N. Bouchiba, S. Sallem, L. Chrifi-Alaoui, and M. B. A. Kammoun, "Optimal tuning of power system stabilizer using genetic algorithm to improve power system stability," Int. Conf. Green Energy Convers. Syst. GECS 2017, 2017, doi: 10.1109/GECS.2017.8066200.

[4] S. Dewangan, "Artificial Bee Colony based FOPID for SMIB System," Int. J. Digit. Appl. Contemp. Res., vol. 5, no. 8, 2017.

[5] M. A. Abdel Ghany and M. A. Shamseldin, "Model reference self-tuning fractional order pid control based on for a power system stabilizer," Int. J. Power Electron. Drive Syst., vol. 11, no. 3, pp. 1333-1434, 2020, doi: 10.11591/ijpeds.v11.i3.pp1333-1343.

[6] M. A. Shamseldin, M. A. Eissa, and A. A. El-samahy, "Practical Implementation of GA-Based PID Controller for Brushless DC Motor," 2015.
[7] A. S. Alkhafaji, A. A. Al-Hayder, and A. S. Hassooni, "Hybrid IWOPSO optimization based marine engine rotational speed control automatic system," Int. J. Electr. Comput. Eng., vol. 10, no. 1, pp. 840-848, 2020, doi: 10.11591/ijece.v10i1.pp840-848.

[8] M. A. Mhawesh, "Performance comparison between variants PID controllers and unity feedback control system for the response of the angular position of the DC motor," Int. J. Electr. Comput. Eng., vol. 11, no. 1, pp. 802-814, 2021, doi: 10.11591/ijece.v11i1.pp802-814.

[9] M. A. Abdel Ghany, M. A. Shamseldin, and A. M. Abdel Ghany, "A novel fuzzy self tuning technique of single neuron PID controller for brushless DC motor," Int. J. Power Electron. Drive Syst., vol. 8, no. 4, 2017, doi: 10.11591/ijpeds.v8i4.pp1705-1713.

[10] N. van Tan, K. N. Dang, P. D. Dai, and L. V. Van, "Position control for haptic device based on discrete-time proportional integral derivative controller," Int. J. Electr. Comput. Eng., vol. 12, no. 1, pp. 269-276, 2022, doi: 10.11591/ijece.v12i1.pp269-276.

[11] W. Zhao and X. Ren, "Neural network-based tracking and synchronization control for nonlinear multi-motor driving servomechanism," Chinese Control Conf. CCC, vol. 2016Augus, pp. 3525-3530, 2016, doi: 10.1109/ChiCC.2016.7553901.

[12] B. Kusumoputro and M. Rifan, "Performance Characteristics of An Improved Single Neuron PID Controller using Additional Error of an Inversed Control Signal," World Congr. Ind. Control Syst. Secur., pp. 5862, 2015.

[13] M. A. Shamseldin, M. Sallam, A. M. Bassiuny, and A. M. Abdel Ghany, "LabVIEW implementation of an enhanced nonlinear PID controller based on harmony search for one-stage servomechanism system, " J. Comput. Appl. Res. Mech. Eng., vol. 12, pp. 4161-4179, 2019, doi: 10.15282/jmes.12.4.2018.13.0359.

[14] "PID Based on a Single Artificial Neural Network Algorithm for Intelligent Sensors," J. Appl. Res. Technol., vol. 10, no. April, pp. 262-282, 2012.

[15] L. Wang and B. Chen, "Single Neuron PID Control of Aircraft Deicing Fluids Rapid Heating System," J. NETWORKS, vol. 8, no. 2, pp. 405-412, 2013, doi: 10.4304/jnw.8.2.405-412.

[16] Q. Wang and Y. Shuang, "A Single Neuron PID Control Algorithm of Memristor-based," Comput. Inf. Syst., vol. 14, no. 20143104, pp. 5023-5030, 2015, doi: 10.12733/jcis14531.

[17] M. A. Abdel Ghany and M. A. Shamseldin, "Parallel distribution compensation PID based on Takagi-Sugeno fuzzy model applied on Egyptian load frequency control," Int. J. Electr. Comput. Eng., vol. 10, no. 5, pp. 5274-5287, 2020, doi: 10.11591/IJECE.V10I5.PP5274-5287.

[18] N. Rajabi and A. Hossein, "Sliding mode trajectory tracking control of a ball - screw - driven shake table based on online state estimations using EKF / UKF," WILEY, no. November 2017, pp. 1-13, 2018, doi: 10.1002/stc. 2133.

[19] R. Majdoul, A. Touati, A. Ouchatti, A. Taouni, and E. Abdelmounim, "Comparison of backstepping, sliding mode and PID regulators for a voltage inverter," Int. J. Electr. Comput. Eng., vol. 12, no. 1, pp. 166-178, 2022, doi: 10.11591/ijece.v12i1.pp166-178.

[20] S. Wang, L. Hou, L. Dong, and H. Xiao, "Adaptive fuzzy sliding mode control of uncertain nonlinear SISO systems," Revis. Control Autom., vol. 24, pp. 33-37, 2011, doi: 10.1016/j.proeng.2011.11.2597.

[21] P. B. Zhao, "Fuzzy Sliding Mode Control of the a-Axis 
WSEAS TRANSACTIONS on COMPUTERS DOI: 10.37394/23205.2021.20.34

With High Torque and High Power."

[22] M. A. Shamseldin, M. Sallam, A. M. Bassiuny, and A. M. A. Ghany, "A new model reference self-tuning fractional order PD control for one stage servomechanism system," WSEAS Trans. Syst. Control, vol. 14, pp. 8-18, 2019.

[23] A. Upadhya, "Identification of Sliding and Pre-sliding Regime Frictio $n$ in a Ball Screw Driven System," in 2017 international conference on Intelligent Computing, Instrumentation and Control Technologies (ICICICT), 2017, pp. 474-477.

[24] W. Netto, R. Lakhani, and S. Meenatchi Sundaram, "Design and performance comparison of different adaptive control schemes for pitch angle control in a Twin-Rotor-MIMO-System," Int. J. Electr. Comput. Eng., vol. 9, no. 5, pp. 4114-4129, 2019, doi: 10.11591/ijece.v9i5.pp4114-4129.

[25] S. Chen and C. Kuo, "Design and implementation of double-integral sliding-mode controller for brushless direct current motor speed control," Adv. Mech. Eng., vol. 9, no. 1, pp. 1-9, 2017, doi: 10.1177/1687814017737724.

[26] P. Govindan, "Evolutionary algorithms-based tuning of PID controller for an AVR system," Int. J. Electr. Comput. Eng., vol. 10, no. 3, pp. 3047-3056, 2020, doi: 10.11591/ijece.v10i3.pp3047-3056.

[27] A. A. E.-S. Adel A. A. El-Gammal, "Adaptive Tuning of a PID Speed Controller For DC Motor Drives Using MultiObjective Particle Swarm Optimization MOPSO, " 2009.

[28] N. A. Elkhateeb and R. I. Badr, "Novel PID Tracking Controller for 2DOF Robotic Manipulator System Based on Artificial Bee Colony Algorithm," Electr. Control Commun. Eng., vol. 13, no. 1, pp. 55-62, 2017, doi: 10.1515/ecce-2017-0008.

\section{BIBLIOGRAPHY OF AUTHORS}

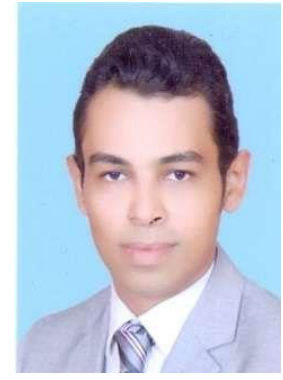

Dr. M A. Abdel Ghany was born in Cairo 22thJuly1988. He received his B. Sc from Higher Technological Institute (Tenth of Ramadan City) 2011, Diploma and M.Sc. in Automatic Control (2012 to 2014) from, Helwan University, Cairo, Egypt. From 20/6/2015 to 2018 he worked as an Assistant Lecturer at Faculty of Computer science Nahda University, Bani Sweif City. He obtained his Ph. D in Automatic Control branch in Faculty of Engineering, Helwan University, Egypt. Now, he worked as a Lecturer at department of Electrical Engineering, Faculty of Engineering October 6 University, Egypt.

https://scholar.google.com/citations?user=kEM 8Dz0AAAAJ\&hl=en

https://orcid.org/0000-0002-5107-6633

$\underline{\text { Scopus Author ID: } 57193606416}$
Mohamed Abdel Ghany, Mohamed Abdelbar Shamseldin

Dr. Mohamed.A. Shamseldin born in Cairo, Egypt, on October 1, 1987. He received the B.Sc. degree in mechatronics engineering in 2010 from faculty of engineering at Helwan, Helwan University, Cairo, Egypt. On December 2012, he received his work in faculty of engineering and technology at Future University in Egypt as an instructor in Mechatronics Engineering Department. He obtained M.Sc. in system automation and engineering management (2012 to 2016) from, Helwan University, Cairo, Egypt. Mohamed was visiting staff at University of Central Lancashire, Preston, UK. His research activity includes studying Artificial Intelligent techniques, electrical machines speed control and robot control.

https://scholar.google.com/citations? user $=\mathrm{xHC6}$ OPgAAAAJ\&hl=ar

https://orcid.org/my-orcid?orcid $=0000-0002-$ $\underline{3993-2265}$

$\underline{\text { Scopus Author ID: } 56410947700}$

\section{Creative Commons Attribution License 4.0 (Attribution 4.0 International, CC BY 4.0)}

This article is published under the terms of the Creative Commons Attribution License 4.0

https://creativecommons.org/licenses/by/4.0/deed.en_US

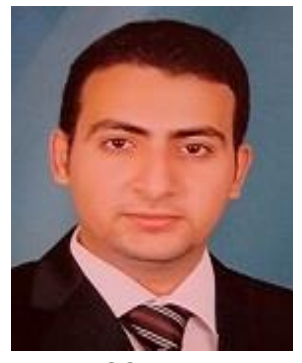

